\title{
Elementary Notions of Quantum Mechanics Erratum
}

KARL K. DARrow, Bell Telephone Laboratories

(Rev. Mod. Phys. 6, 23, 1934)

Page 28, column 1, line 10 from bottom: for "This" read "The phasespeed or wave speed."

\section{On the Statistical Theory of Errors}

Errata

W. Edwards Deming and Raymond T. Birge

(Rev. Mod. Phys. 6, 119, 1934)

Page 135, second column, line 10 , for "small" read "large."

Page 140, first column, line 2 of text should read " $u=$ const." instead of "s= const."

Page 146, in the heading of Table IV, the slant bar after the $s$ in Eq. (39) should be removed. The equation will then agree with Eq. (39) as it occurs in the text near the top of the page.

Two articles on related material, which should have been mentioned, are Paul R. Rider, A Survey of the Theory of Small Samples, Annals of Mathematics 31, 577-628 (1930). J. F. Tocher, What is Probable Error? a lecture delivered at the Institute of Chemistry of Great Britain and Ireland, April 24, 1931. Copies may be obtained from the Institute, 30 Russell Square, London, W. C. 1 , at $2 s / 6 d$. 